\title{
Collection Development Policies in the Information Age
}

\section{Dan C. Hazen}

Collection development policies as traditionally conceived are static, reactive, and of little practical utility. They have outlived their purpose. Research librarians will better serve both themselves and their users by devising flexible guides to all the information associated with particular fields of study. Local collections will comprise a part of these "information maps," but only within the context of a richer and less bounded universe of scholarly resources.

ibrary orthodoxy has congealed around a number of purportedly self-evident truths, among them a universal need for collection development policies. These documents, according to the literature, are indispensable antecedents to competent selection. ${ }^{1}$ They both explain the library to and defend it from its patrons. They provide a conceptual framework for budget requests. And they are essential for cooperative collection development and resource sharing.

As scholarship, information resources, and libraries continue to change, these assertions may no longer hold. A critical reexamination of the role of collection development policy is very much in order. The purpose of this essay is to stimulate discussion on whether and how we should codify our endeavor.

\section{MONUMENTS OF DEFENSIVENESS}

Collection development policies keep us out of trouble with our users. Public libraries use them in order to reject inflammatory or sectarian materials on the one hand, and to retain potentially offensive items on the other. Academic libraries most frequently invoke these policies when the real issue is money. Research libraries frame their mission in terms of service to the campus community of students and scholars. Yet we respond to new demands, most commonly from new academic programs or faculty members, by citing our collections policy to ratify the status quo. The economic dilemmas may be real, but our mandate is clear. Policy-based decisions to exclude ephemera, nonprint formats, or any other category of research resources similarly establish arbitrary boundaries that in fact reflect fiscal or (even less defensibly) procedural necessities. We use collection development policies to defend our frontiers.

\section{ENSHRINEMENTS OF OBSOLESCENCE}

Formulating a collection development policy requires librarians first to categorize the world. Collections policies thus divide information resources by subject, format, user level, language, size, durability, and so on. Having established pigeonholes for the entire universe of recorded knowledge, librarians can-in theory-decide what to do with specific items by matching each to its slot and then checking whether the category is

Dan C. Hazen is Librarian for Latin America, Spain, and Portugal at the Harvard College Library, Cambridge, Massachusetts 02138. 
marked for inclusion or exclusion. A rigid and comprehensive structure of categories ensures that the policy will work.

The ambition is of course illusory. Our best efforts to produce meaningful sets of pigeonholes have fallen well short of representing all recorded knowledge. As the Research Libraries Group Conspectus demonstrates, even these partial syntheses have collapsed of their own weight. And any such system is of little utility for the selectors who must negotiate an endless stream of new materials, often described only minimally and increasingly crossing traditional boundaries of format and discipline.

\section{Collection development policies reify scholarly distinctions that no longer carry meaning.}

The search for airtight taxonomies is flawed because neither library resources nor scholarship pay them heed. The conceptual structure of nineteenth-century scholarship might have conformed to clear subject fields and canonical sources. Interdisciplinary, multimedia research is the byword of our postmodern academy, and both scholars and the materials they produce routinely cross traditional boundaries. Collection development policies reify scholarly distinctions that no longer carry meaning. They are exercises in obsolescence that cater to nostalgic longings for order, precision, and prescription.

\section{CODIFICATIONS OF DECLINE}

Libraries typically hang their arguments for materials budgets on the need to sustain acquisitions at the levels delineated in collection development policies. Yet most libraries' collection budgets are either lagging inflation or in actual decline. Wish as we may, librarians cannot make documents descriptive of internal practice into binding guides for the institution at large: our paper pronouncements are irrelevant. And so we ceaselessly debate about whether and how to adjust our collection development policies. When we recast them to reflect (ever-diminishing) reality, are we simply acting responsibly by providing the information that our users and potential cooperative partners require? Or are we capitulating before a philistine academic bureaucracy? Whichever the conclusion, our policies codify decline.

\section{SELECTION IN THE POSTMODERN ACADEMY, CODIFICATION IN THE VIRTUAL WORLD}

Traditional collection development policies will not meet our needs. More flexible documents, on the other hand, could be useful to users, librarians, and even administrators.

Libraries and their collections address the increasingly complicated needs of users both current and future. The essential resources are less and less limited to local holdings and represent increasingly varied formats. Today's students and scholars routinely consult traditional books and journals. They rely on such nonprint media as sound and video recordings. Collections of ephemera and archival sources are likewise important, along with museum holdings and materials in foreign repositories. And electronic information is ever more prevalent, both in portable formats and as online products.

Researchers must master card catalogs, online catalogs, bibliographic databases, printed indexes and bibliographies, electronic indexes and bibliographies, guides to foreign repositories, descriptions of nonprint and media collections whether held within or outside libraries, and the full range of Internet resources and protocols. Scholars also rely on direct contact with their peers. The panorama is confusing and seems destined to become even more complex. Nonetheless, and as in the past, part of the library's job is to make sense of this abundance.

Discipline-specific resource maps, encompassing the full range of information resources appropriate to each field and using electronic technology to ensure flexible responses, could provide a solu- 
tion. Hypertext information maps, for example, might offer multiple pathways through all of a field's information resources while accommodating different kinds of inquiries and different sorts of users. ${ }^{2}$ Those using these hypertext systems would create their own tunnels and paths. Researchers could, for instance, search for recent, locally held books and articles on street children in Recife, Brazil; broaden their inquiry to cover the full range of print and nonprint materials on family life in Brazil; move on to English-language bibliographies and Internet discussion groups concerned with social conditions in Latin America as a whole; and finally consider videos and films on children in Mexico City.

This condensed example illustrates some of the dimensions of inquiry that the proposed "hypertext information maps" might accommodate. One starting point would be "subject access." Researchers often approach bibliographic tools with a topic in mind; so might they approach these hypertext maps to information of all types and at all locations. Users could also focus on the different formats of information, limiting their inquiries to any desired combination of books, journal articles, sound recordings, electronic files, archival collections, museum holdings, specialized research centers, personal contacts, and so on. The location of resources would provide another organizing principle. A fourth approach could address different levels of comprehensiveness or user sophistication. A novice in some field might limit his or her investigation to recent reference books in English; a specialist might seek all available materials regardless of language, type, location, date, or format. The dimensions of these information maps would in some ways resemble, on a scale encompassing all sources and formats, the "faceted" classification systems that have attempted to capture the multiple dimensions of single publications within a manual environment.

Flexible descriptions that encompass all formats of information and resources both local and remote will require continuous adjustment as each field's methods and materials evolve. Libraries will therefore have to focus continuously on users' priorities and needs. Strategies for hard copy acquisitions will follow and derive from these general analyses.

\section{Flexible descriptions that encompass all formats of information, and resources both local and remote will require continuous adjustment as each field's methods and materials evolve.}

The library can solidify its own sense of purpose, and also point the campus toward the future, by recasting its documentation in terms of all the research resources associated with its users and the fields they represent. Insisting on inflexible, site-specific codifications for our hard copy acquisitions will only mire us in the past.

\section{REFERENCES AND NOTES}

1. The literature on collection development policies is massive. See the Collection Development Policies Committee of the Collection Development and Evaluation Section, RASD, "The Relevance of Collection Development Policies: Definition, Necessity, and Applications," RQ 33 (Fall, 1993), 65-74, for a good recent summary that includes analysis, policymaking advice, and a basic bibliography.

2. The task is extremely complex. Making sense of apparent chaos almost inevitably involves categorization - the utilization of pigeonholes. A great deal thus depends on delineating imaginative categories and flexible uses. Hypertext pathways, moreover, may reflect only their creators' notion of plausible connections: their open-endedness can be more apparent than real. Flexibility is difficult to attain. 


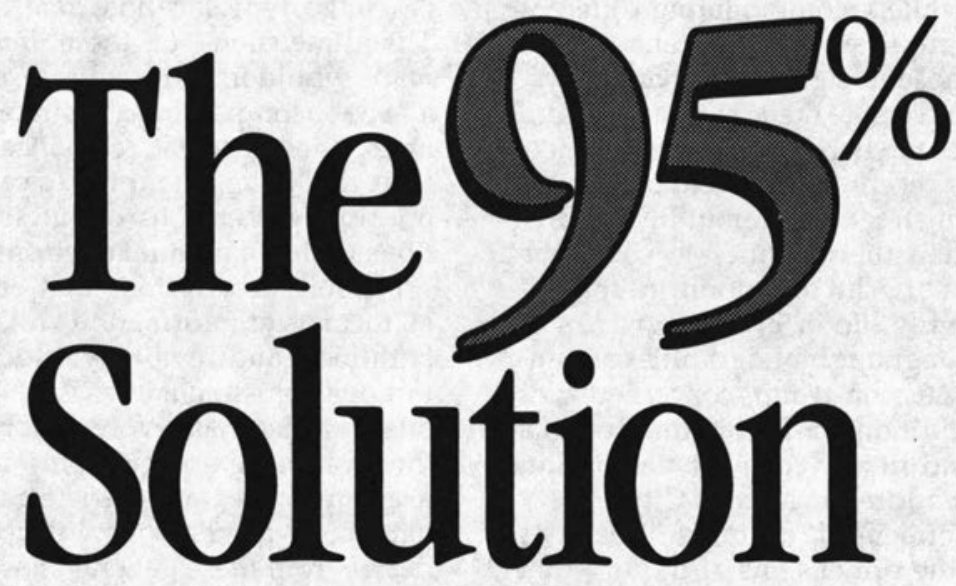

You get one chance with authority control, so it's important to get it done right. LTI guarantees that its affordable, machine-only authority control will link $95 \%$ or more of your library's controlled headings to an LC or LTI authority record. No exceptions! No excuses!

When manual review is requested, only professional librarians are used as editors and link rates approach $100 \%$.

LTI maintains the complete LC MARC authority files (updated weekly), supplemented by 610,000 LTI authority records and 625,000 LTI-created cross references from incorrect heading forms to the LC authorized heading.

Contact LTI for more information on authority record link results.

"Authority Control for the 21st Century"

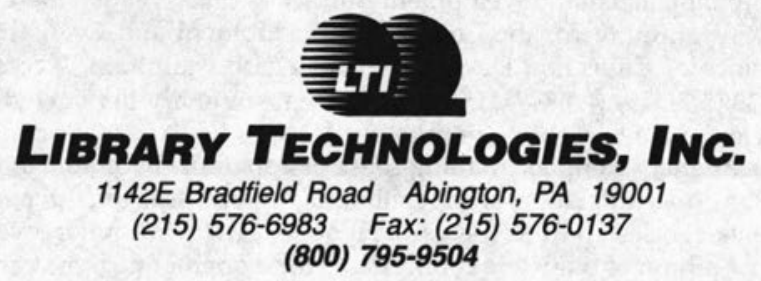

